OAK RIDGE

NATIONAL LABORATORY

MANAGED BY UT-BATTELLE

FOR THE DEPARTMENT OF ENERGY

\title{
Comparative Calculations of Solubility Equilibria
}

\author{
E. C. Beahm \\ R. K. Toghiani \\ C. F. Weber
}

Tanks

Focus Area 



\title{
LETTER REPORT
}

To:

\author{
C. P. McGinnis
}

Subject of Document: Comparative Calculations of Solubility Equilibria

Type of Document: $\quad$ Letter Report

Authors:

E. C. Beahm, R. K. Toghiani, and C. F. Weber

Date of Document: July 2000

\section{Internal Distribution}

1. M. R. Ally, $4500 \mathrm{~N}, \mathrm{MS}-6206$

2. A. G. Croff, $4500 \mathrm{~N}, \mathrm{MS}-6178$

3. R. T. Jubin, 4501 , MS-6223

4. L. E. McNeese, $4500 \mathrm{~N}$, MS- 6228

5. S. M. Robinson, 3017 , MS-6044

6-10. C. F. Weber, 6011, MS-6370

11. Central Research Library

12. ORNL Laboratory Records-RC

13-14. ORNL Laboratory Records-OSTI

\section{External Distribution}

15. Harry Babad, Babad Technical Services, 2540 Cordoba Court, Richland, WA 99352

16. Ed Beahm, 106 Cooper Circle, Oak Ridge, TN 37830

17. Dan Herting, Fluor Daniel, P. O. Box 1970, MSIN T6-07, Richland, WA 99352

18. T. Albert Hu, CH2M Hill Hanford Group, P.O. Box 1300, MSIN R2-11, Richland, WA 99352

19. Randy Kirkbride, Numatec Hanford Company, P. O. Box 1300, MSIN R3-73, Richland, WA 99352

20. Jeff Lindner, DIAL, 205 Research Boulevard, Starkville, MS 39759-9734

21. Graham MacLean, FFS, P.O. Box 1050, MSIN G3-10, Richland, WA 99352

22. J. R. Noble-Dial, U.S. Department of Energy, Oak Ridge Operations Office, P.O. Box 2001, Oak Ridge, TN 37830-8620

23-27. R. K. Toghiani, Mississippi State University, Campus Mailstop 9595, Etheredge Engr. Bldg., Room 129, P.○. Box 9595, Mississippi State, MS 39762

28. Tanks Focus Area Program Manager, c/o T. P. Pietrok, U.S. Department of Energy, Richland Operations Office, P.O. Box 550, MSIN K8-50, Richland, WA 99352

29-36. Tanks Focus Area Technical Team, c/o B. J. Williams, Pacific Northwest National Laboratory, P.O. Box 999, MSIN K9-69, Richland, WA 99352

\section{LETTER REPORT}





\section{CONTENTS}

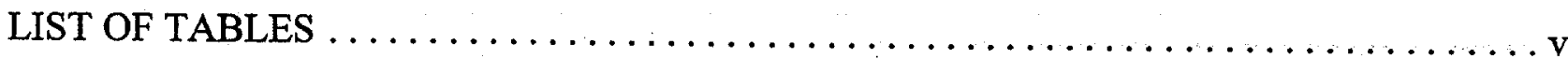

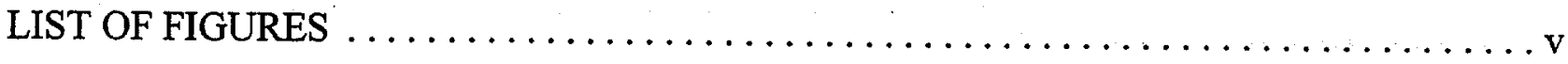

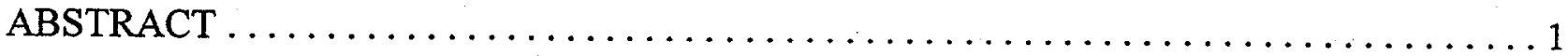

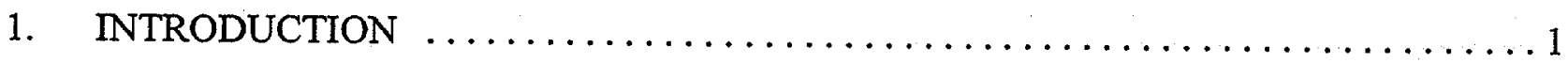

2. ASSESSMENT OF UNCERTAINTY IN THERMOCHEMICAL DATA $\ldots \ldots \ldots \ldots$.

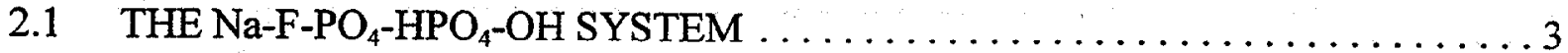

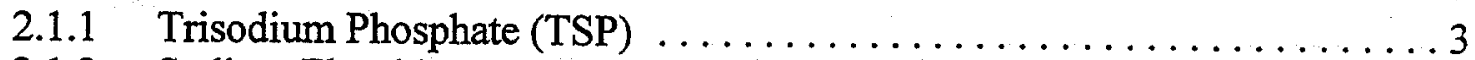

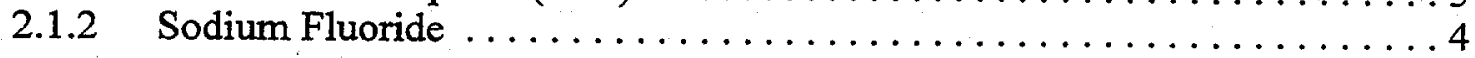

2.1.3 Sodium Fluoride-Phosphate Double Salt (DS) $\ldots \ldots \ldots \ldots \ldots \ldots \ldots 4$

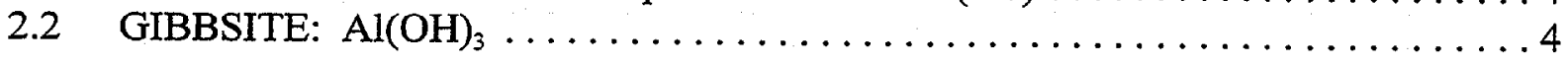

3. CALCULATED RANGES OF UNCERTAINTY-SOLGAS RESULTS $\ldots \ldots \ldots \ldots 5$

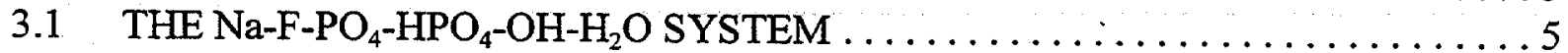

3.2 THE ALUMINA-SODIUM PHOSPHATE-SODIUM FLUORIDE-

SODIUM FLUORIDE-PHOSPHATE SYSTEM $\ldots \ldots \ldots \ldots \ldots \ldots \ldots \ldots$

4. COMPARISON OF CALCULATIONS USING ESP AND SOLGASMIX $\ldots \ldots \ldots \ldots 10$

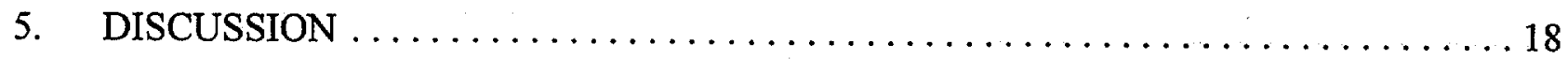

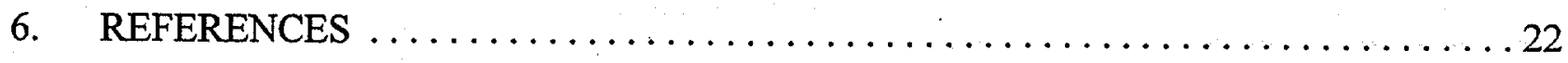





\section{LIST OF TABLES}

Table

1 Gibbs Energies of Formation and their uncertainties

Page

2 Equilibrium constants for the reaction of alumina and hydroxide $\ldots \ldots \ldots \ldots \ldots \ldots$

3 Solubility values for sodium fluoride at $25^{\circ} \mathrm{C}$

\section{LIST OF FIGURES}

Figure

$\underline{\text { Page }}$

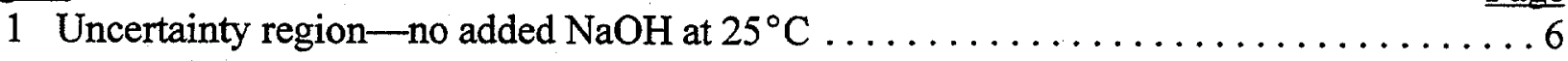

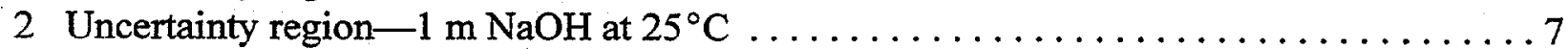

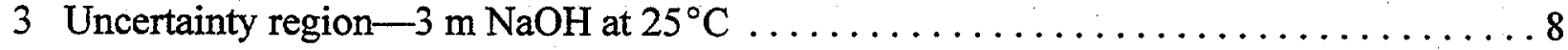

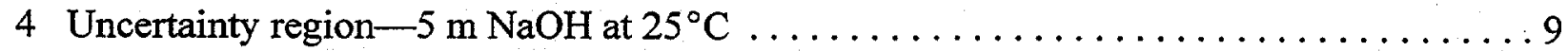

5 Minimum operating region: $3.0 \mathrm{~m} \mathrm{NaOH}$ at $25^{\circ} \mathrm{C}, \mathrm{N}_{\mathrm{PO}_{4}}+\mathrm{N}_{\mathrm{F}}+\mathrm{N}_{\mathrm{Al}}=0.3 \mathrm{~mol} / \mathrm{kg} \ldots \ldots 11$

6 Maximum operating region: $3.0 \mathrm{~m} \mathrm{NaOH}$ at $25^{\circ} \mathrm{C}, \mathrm{N}_{\mathrm{PO}_{4}}+\mathrm{N}_{\mathrm{F}}+\mathrm{N}_{\mathrm{Al}}=0.3 \mathrm{~mol} / \mathrm{kg} \ldots \ldots 12$

7 Uncertainty regions: $3.0 \mathrm{~m} \mathrm{NaOH}$ at $25^{\circ} \mathrm{C}, \mathrm{N}_{\mathrm{PO}_{4}}+\mathrm{N}_{\mathrm{F}}+\mathrm{N}_{\mathrm{Al}}=0.3 \mathrm{~mol} / \mathrm{kg} \ldots \ldots \ldots 13$

8 Comparison calculations for ESP and SOLGASMIX, using $1 \mathrm{~m} \mathrm{NaOH}$ at $25^{\circ} \mathrm{C} \ldots \ldots 14$

9 Comparison calculations for ESP and SOLGASMIX, using $3 \mathrm{~m} \mathrm{NaOH}$ at $25^{\circ} \mathrm{C} \ldots \ldots 15$

10 Comparison calculations for ESP and SOLGASMOX, using $5 \mathrm{~m} \mathrm{NaOH}$ at $25^{\circ} \mathrm{C} \ldots \ldots 16$

11 Comparison calculations for ESP and SOLGASMIX, using water at $25^{\circ} \mathrm{C} \ldots \ldots \ldots 17$

12 Temperature dependence of sodium fluoride solubility $\ldots \ldots \ldots \ldots \ldots \ldots \ldots \ldots \ldots$ 



\title{
COMPARATIVE CALCULATIONS OF SOLUBILITY EQUILIBRIA
}

\author{
E. C. Beahm, R. K. Toghiani, ${ }^{*}$ and C. F. Weber ${ }^{\dagger}$
}

\begin{abstract}
The uncertainties in calculated solubilities in the Na-F- $-\mathrm{PO}_{4}-\mathrm{HPO}_{4}-\mathrm{OH}$ system at $25^{\circ} \mathrm{C}$ for $\mathrm{NaOH}$ concentrations up to $5 \mathrm{~mol} / \mathrm{kg}$ were assessed. These uncertainties were based on an evaluation of the range of values for the Gibbs energies of the solids. Comparative calculations using the Environmental Simulation Program (ESP) and SOLGASMIX indicated that the variation in activity coefficients with $\mathrm{NaOH}$ concentration is much greater in the ESP code than in SOLGASMIX. This resulted in ESP calculating a higher solubility in water and a lower solubility in $\mathrm{NaOH}$ concentrations above $1 \mathrm{~mol} / \mathrm{kg}$. There was a marked discrepancy in the solubilities of the pure components sodium fluoride and trisodium phosphate predicted by ESP and SOLGASMIX. In addition, different solubilities for these components were obtained using different options in ESP. Because of these observations, a Best Practices Guide for ESP will be assembled.
\end{abstract}

\section{INTRODUCTION}

It is necessary to predict the solubilities of components in retrieval solutions as well as in wash solutions and leachates from pretreatment processes. Such predictions will help to ensure that the undissolved-solid content is within specifications and to avoid the formation of solids that may plug transfer lines, cause retrieval difficulties, or foul separations material and equipment. The Environmental Simulation Program (ESP), supplied by OLI Systems, Inc. (Morris Plains, NJ), is being used at Hanford to calculate process chemical equilibria. Both those who perform ESP calculations and those who use the results need to be aware of potential uncertainties that could result in errors in the distribution of material between water solutions and solids. The ESP includes a thermochemical data base, a solver for calculating equilibria, and the ability to simulate unit operations.

There are three constituents in thermochemical modeling: (1) the computer, (2) the computer routine to calculate equilibria, and (3) the data. Computers are readily available, and equilibrium solver routines such as SOLGASMIX ${ }^{1}$ can effectively be adapted to complex systems. Nowadays, almost the entire effort in modeling involves data evaluation and fitting. It is important that all of the data be internally consistent. Standard data bases such as CODATA ${ }^{2}$ were assembled to provide

*Mississippi State University, Mississippi State, MS 39762.

${ }^{\dagger}$ Computational Physics and Engineering Division. 
such consistency. In addition to consistency, the accuracy of thermochemical data should also be assessed. Each value used in a calculation will have some uncertainty. The distribution of species found in a calculation will show as points in a range of values that come from the accumulation of uncertainties.

The strength of a comprehensive calculational routine, such as ESP, lies in its extensive data base for large systems containing many components. This strength is also a potential weakness in that the uncertainty in both the data and the calculated distribution of species is opaque to the user. Several different approaches can be used to provide evidence that the calculations are reliable and to estimate uncertainty.

Calculations based on the results of experimental tests have been made. ${ }^{3}$ These calculations serve as a comparison between experimental measurements and calculations. However, they cannot ensure that the results will be valid for combinations of species that are different from those used in the tests. Also, because the anion and cation balance is never perfect in analytical chemistry results, some heuristic adjustments are always necessary. This means that a direct comparison can never be made between model calculations and test results. Other techniques to validate ESP include comparison calculations using another equilibrium solver routine, comparison of standard thermodynamic values for key species with well-assessed data, and evaluations of consistency in activity coefficients using the Gibbs-Duhem equation.

Solubility in retrieval and process solutions will depend on temperature, hydroxide ion concentration, and ionic strength. In a previous study, ${ }^{4}$ it was shown that solubility in the $\mathrm{Na}-\mathrm{F}-\mathrm{PO}_{4}-\mathrm{HPO}_{4}-\mathrm{OH}-\mathrm{H}_{2} \mathrm{O}$ system markedly decreased with temperature. Also, it was demonstrated that the addition of fluoride to solutions containing phosphate would result in a gel-like material, $\mathrm{Na}_{7}\left(\mathrm{PO}_{4}\right)_{2} \mathrm{~F} \cdot 19 \mathrm{H}_{2} \mathrm{O}$, which significantly decreases the concentration of phosphate that can remain in solution. The assessment of data for that effort has been used in a series of calculations whereby these data, coupled with a version of the SOLGASMIX solver routine, are used in comparisons of results from ESP. The SOLGASMIX calculations include uncertainty in calculated results that arises from uncertainty in the thermochemical data. In this way, we can see where the ESP results fall in comparison to the realm of uncertainty based on the data assessment. Results of ESP 
calculations that fall outside the uncertainty range of the SOLGASMIX results will warrant further evaluation to determine the cause of the discrepancy.

\section{ASSESSMENT OF UNCERTAINTY IN THERMOCHEMICAL DATA}

Uncertainties in standard free energies of formation for trisodium phosphate, sodium fluoride, sodium phosphate-fluoride double salt, and gibbsite were evaluated. These uncertainties were then used to calculate ranges of uncertainty in solubilities, as shown in Sect. 3.

\subsection{THE Na-F-PO 4 - $\mathrm{HPO}_{4}$-OH SYSTEM}

In previous studies, we estimated thermodynamic parameters for the aqueous system Na-F- $-\mathrm{PO}_{4}-\mathrm{HPO}_{4}-\mathrm{OH}$ and used them to construct a comprehensive model of solubility behavior. ${ }^{4,5}$ In the present study, it was useful to examine the uncertainties in these parameters and the resulting uncertainties in solubility predictions. While this analysis only considered nominal temperatures $\left(25^{\circ} \mathrm{C}\right)$, the results are probably applicable throughout the range $0-100^{\circ} \mathrm{C}$.

\subsubsection{Trisodium Phosphate (TSP)}

The principal solid used in the current study was $\mathrm{Na}_{3} \mathrm{PO}_{4} \cdot 12 \mathrm{H}_{2} \mathrm{O} \cdot 1 / 4 \mathrm{NaOH}$, which precipitates at temperatures under $65^{\circ} \mathrm{C}$ and at moderate caustic concentrations. At $25^{\circ} \mathrm{C}$, two values for the Gibbs Energy of Formation were found-one for high caustic levels $\left(\mu^{\circ} / R T=-1926.923\right)$ and one for high phosphate levels $\left(\mu^{0} / R T=-1927.4\right)$. The latter predicts excess solid (i.e., low solubility) in the high caustic region but describes well the invariant point in transferring to the disodium phosphate region. The former gives excellent results for high caustic concentrations but fails to properly describe the invariant point. Between the two values, all TSP regions can be described. The uncertainty for Gibbs energy is assumed to be the difference between these two values; for our purposes, the nominal value is the high caustic value. 


\subsubsection{Sodium Fluoride}

The solubility values for the pure salt show considerable scatter. The uncertainty is selected such that almost all the solubility data are bracketed. For the nominal Gibbs Energy of Formation $\left(\mu^{0} / R T=-219.391 \pm \delta\right)$, the uncertainty $\delta=0.2$ accomplishes this goal.

\subsubsection{Sodium Fluoride-Phosphate Double Salt (DS)}

The value of the Gibbs Energy of Formation $\left(\mu^{0} / R T=-3512.445\right)$ was selected to minimize error residuals. However, the sum of squared error changed very little as this nominal value varied up to about \pm 0.3 . Assuming this to be a good measure of the standard deviation, the true value must lie within three standard deviations. Hence, the uncertainty limit was chosen as \pm 1 .

Using these estimates of uncertainty in the Gibbs Energies of Formation for all three solids, it was possible to predict mean, high, and low values for solubilities. The different values for Gibbs energies are given in Table 1.

Table 1. Gibbs Energies of Formation and their uncertainties

\begin{tabular}{ccc}
\hline & \multicolumn{2}{c}{ Gibbs Energy of Formation, $\mu^{0} / R T$} \\
\cline { 2 - 3 } Solid & Mean & Uncertainty \\
\hline TSP & -1926.923 & \pm 0.5 \\
NaF & -219.391 & \pm 0.2 \\
DS & -3512.445 & \pm 1.0 \\
\hline
\end{tabular}

\section{$2.2 \quad$ GIBBSITE: $\mathrm{Al}(\mathrm{OH})_{3}$}

Wesolowski evaluated data at temperatures from $0-100^{\circ} \mathrm{C}$, including the results from several researchers. ${ }^{6}$ Apps and Neil had carried out a similar study earlier. ${ }^{7}$ Each researcher obtained a result for the equilibrium constant of the reaction $\mathrm{Al}(\mathrm{OH})_{3}+\mathrm{OH}^{-}=\mathrm{Al}(\mathrm{OH})_{4}^{-}$. 
5

The values at various temperatures are shown in Table 2 .

Table 2. Equilibrium constants for the reaction of alumina and hydroxide

\begin{tabular}{cccc}
\hline & \multicolumn{2}{c}{$\log 10(\mathrm{~K})$} & \\
\cline { 2 - 4 } $\mathrm{T}\left({ }^{\circ} \mathrm{C}\right)$ & Reference 6 & Reference 7 & Difference \\
\hline 0 & 1.472 & 1.679 & -0.207 \\
25 & 1.143 & 1.276 & -0.133 \\
50 & 0.814 & 0.889 & -0.075 \\
60 & 0.684 & 0.740 & -0.056 \\
100 & 0.184 & 0.184 & 0 \\
\hline
\end{tabular}

Using the different values of these two significant studies suggests that an uncertainty of 0.15 is reasonable at $25^{\circ} \mathrm{C}$. This value relates directly to the uncertainties of the free energies, since equilibria such as these are used to derive them.

\section{CALCULATED RANGES OF UNCERTAINTY-SOLGAS RESULTS}

\subsection{THE Na-F-PO ${ }_{4}-\mathrm{HPO}_{4}-\mathrm{OH}-\mathrm{H}_{2} \mathrm{O}$ SYSTEM}

Figures 1-4 show results of calculations based on no added $\mathrm{NaOH}, 1 \mathrm{~m} \mathrm{NaOH}, 3 \mathrm{~m} \mathrm{NaOH}$, and $5 \mathrm{~m} \mathrm{NaOH}$, respectively. The heavy dark line in each figure was calculated using the mean free energy values; the other two lines span the uncertainty. In each case, the area above the lines is the region where solids would form. Thus, the lines represent the solubility.

The points in Figs. 2 and 3 indicate experimental results at the indicated compositions. The solid points denote compositions where solids were observed, and the open points represent compositions where no solids were found. The decrease in solubility with increasing $\mathrm{NaOH}$ concentration can be seen by comparing Figs. 1-4 in sequence. 


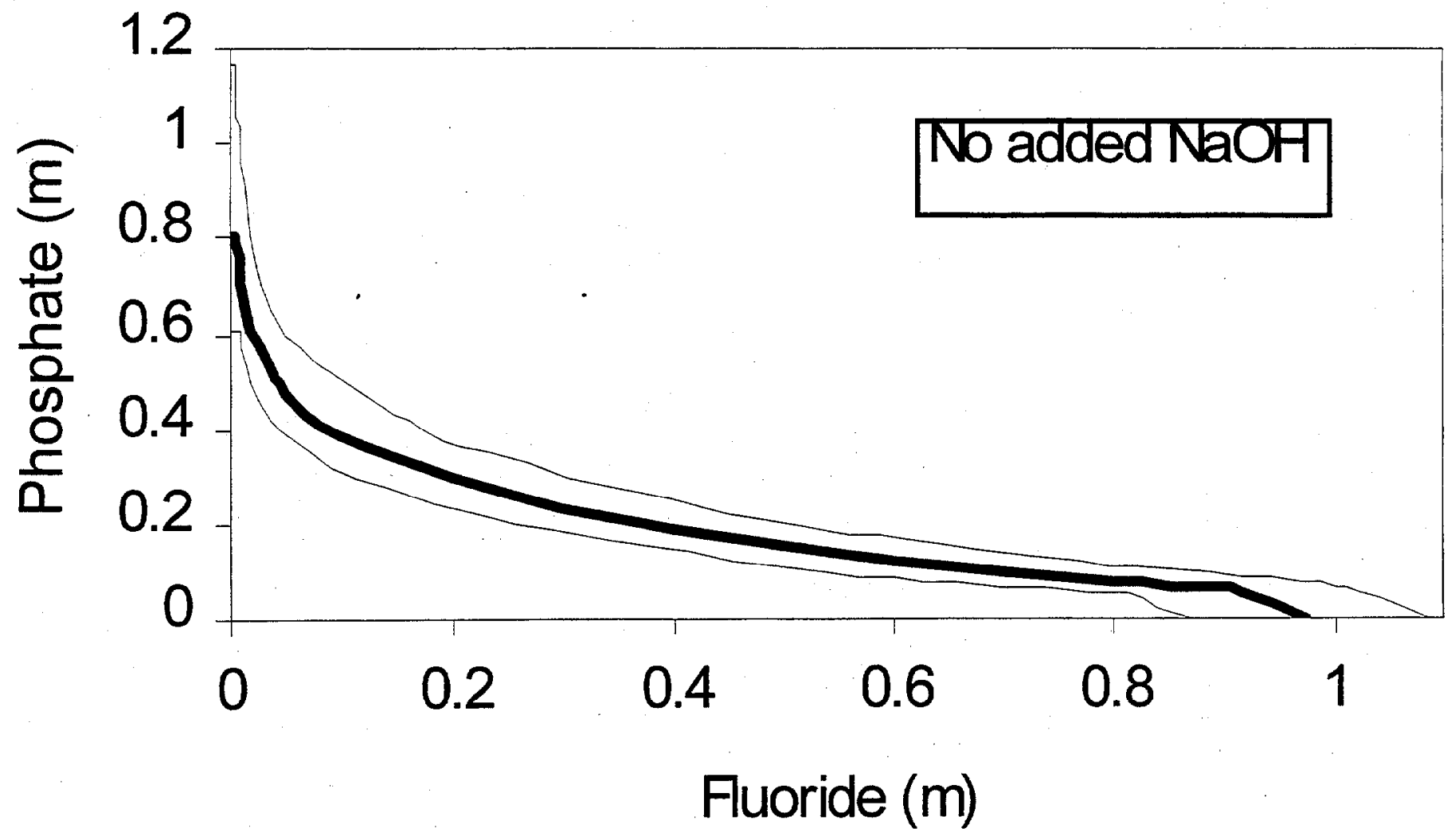

Fig. 1. Uncertainty region-no added $\mathrm{NaOH}$ at $25^{\circ} \mathrm{C}$. 


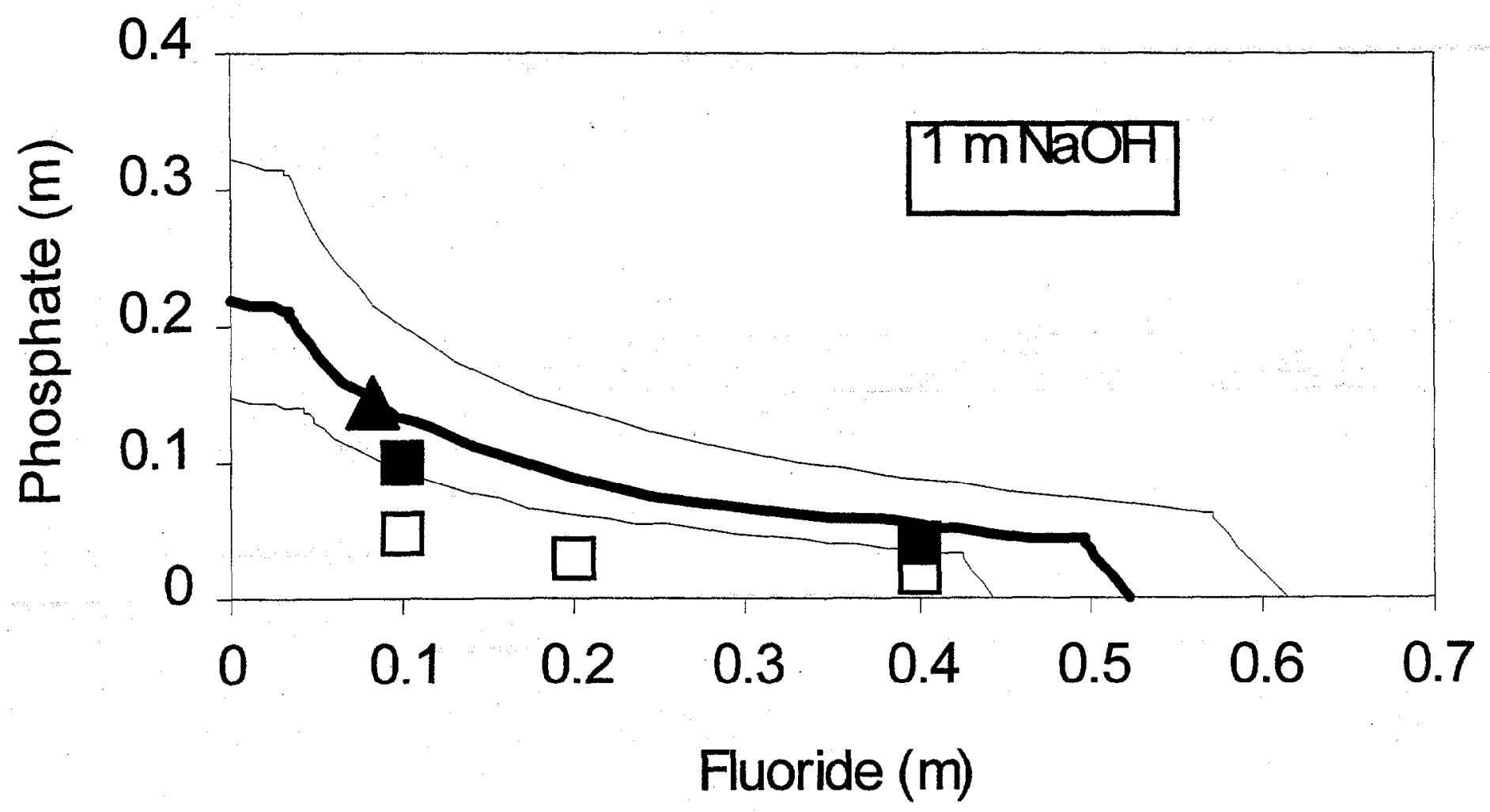

Fig. 2. Uncertainty region-1 $\mathrm{m} \mathrm{NaOH}$ at $25^{\circ} \mathrm{C}$. 
Phosphate $(\mathrm{m})$



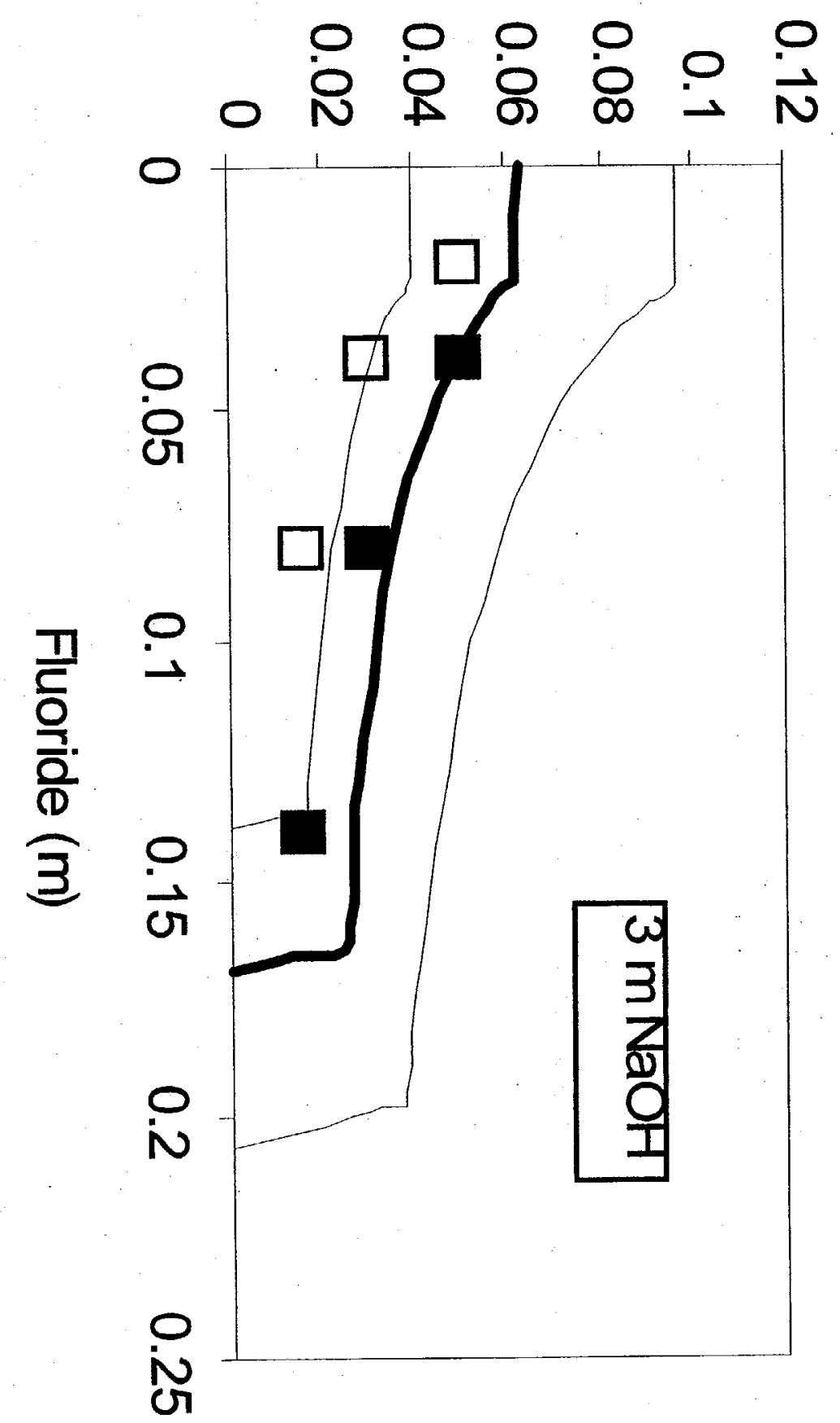




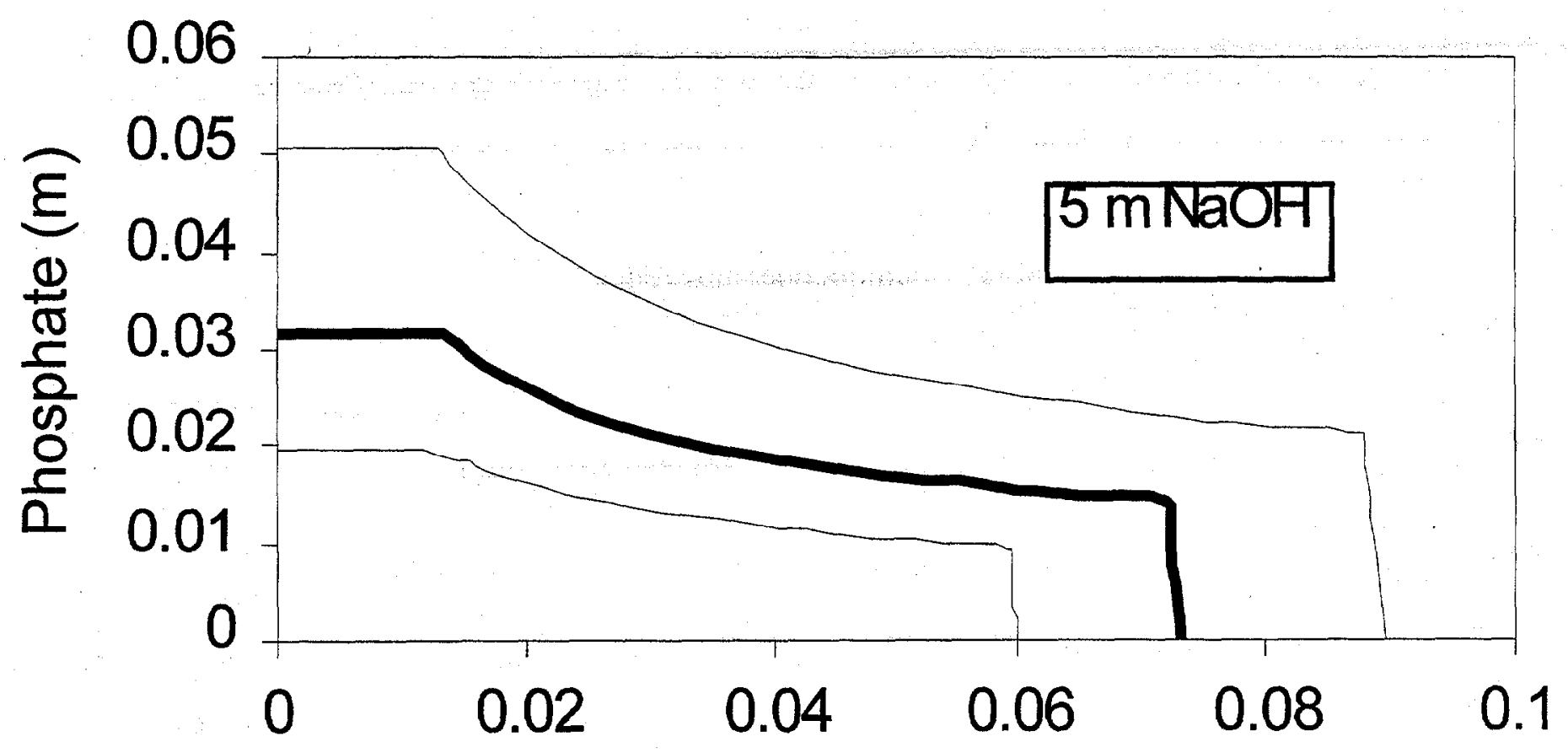

Fluoride (m)

Fig. 4. Uncertainty region-5 $\mathrm{m} \mathrm{NaOH}$ at $25^{\circ} \mathrm{C}$. 


\subsection{THE ALUMINA-SODIUM PHOSPHATE-SODIUM FLUORIDE-SODIUM FLUORIDE-PHOSPHATE SYSTEM}

With the addition of alumina to the system, the calculations must be represented by a ternary diagram, as shown in Figs. 5-7. Because three components are represented on a twodimensional plot, the total concentration must be fixed. In these figures, the concentrations $\mathrm{N}_{\mathrm{PO}_{4}}+\mathrm{N}_{\mathrm{F}}+\mathrm{N}_{\mathrm{Al}}=0.3 \mathrm{~mol} / \mathrm{kg}$, where $\mathrm{N}_{\mathrm{PO}_{4}}, \mathrm{~N}_{\mathrm{F}}$, and $\mathrm{N}_{\mathrm{Al}}$ represent the molalities of phosphate, fluoride, and aluminate, respectively. In all cases, the calculations were performed by assuming a temperature of $25^{\circ} \mathrm{C}$ and a $\mathrm{NaOH}$ concentration of $3.0 \mathrm{~m}$.

In Fig. 5, the region labeled "minimum operating region" was calculated based on the most negative values for the Gibbs Energy of Formation of solids within the uncertainty ranges described in Sect. 2. This resulted in the maximum possibility for solid formation consistent with the present data assessment. The minimum operating region is the area where solids are not predicted to form. The other regions of Fig. 5 indicate which solids would be present. As indicated in Sect. 2.1, TSP refers to trisodium phosphate and DS refers to the sodium fluoride-phosphate double salt.

In Fig. 6, the region labeled "maximum operating region" was based on the most positive values for the Gibbs Energy of Formation of solids within the uncertainty ranges described in Sect. 2. This resulted in the minimum possibility for solid formation consistent with the data assessment. The maximum operating region is the area where no solids would form; it is larger than the minimum operating region in Fig. 5.

In Fig. 7, the "operating region" denotes the range of compositions where no solids form based on calculations that employed the most negative values for the Gibbs Energy of Formation. (The same as minimum operating region in Fig. 5.) The uncertainty regions encompass the composition ranges where solids do not form when the Gibbs Energy of Formation are at their most positive values (cf. Fig. 6).

\section{COMPARISON OF CALCULATIONS USING ESP AND SOLGASMIX}

Figures 8-11 show calculated solubilities in the Na-F- $-\mathrm{PO}_{4}-\mathrm{HPO}_{4}-\mathrm{OH}-\mathrm{H}_{2} \mathrm{O}$ system using ESP and SOLGASMIX. The SOLGASMIX calculations, which are based on data described in Sect. 2, are the same as those in Sect. 3. 


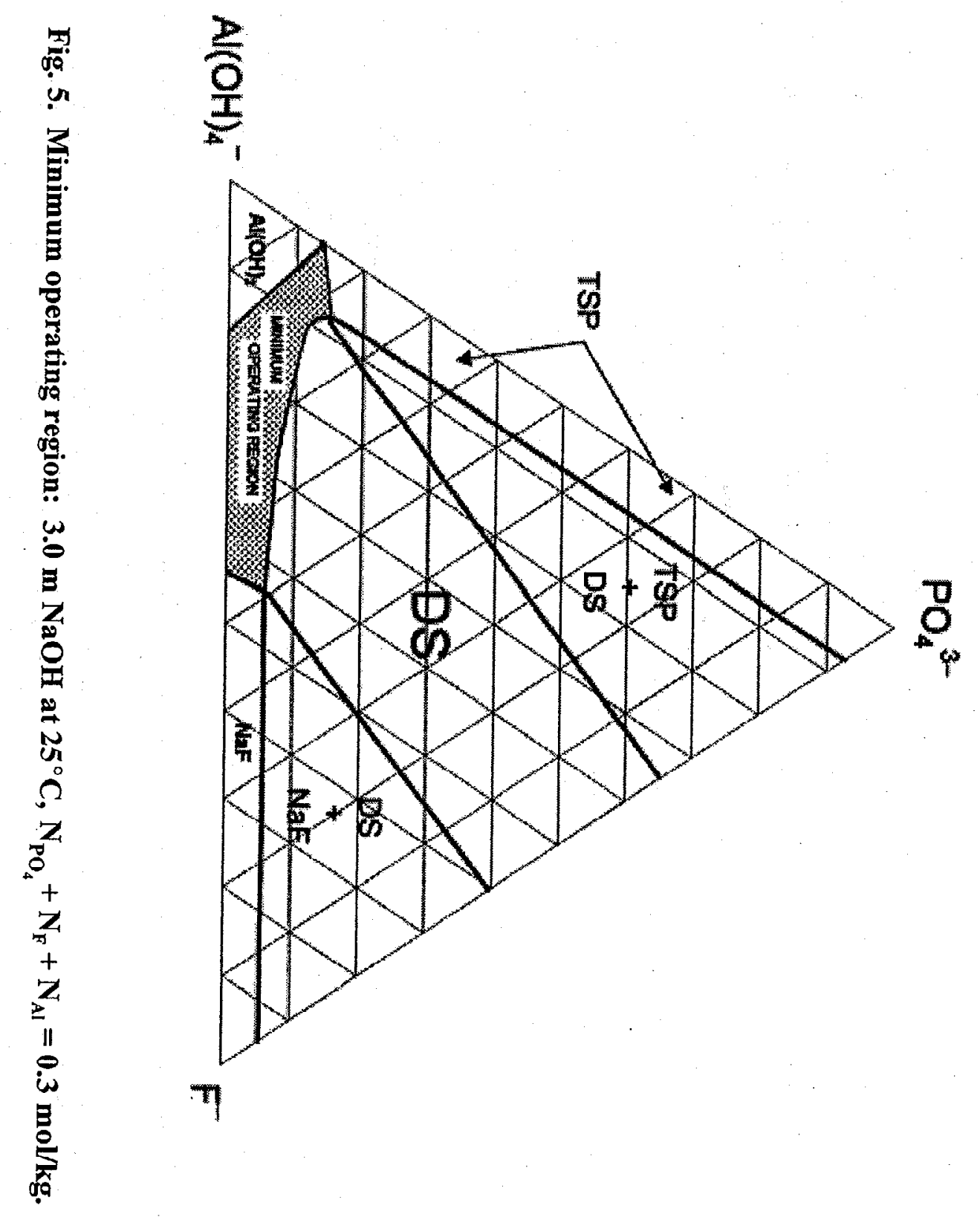




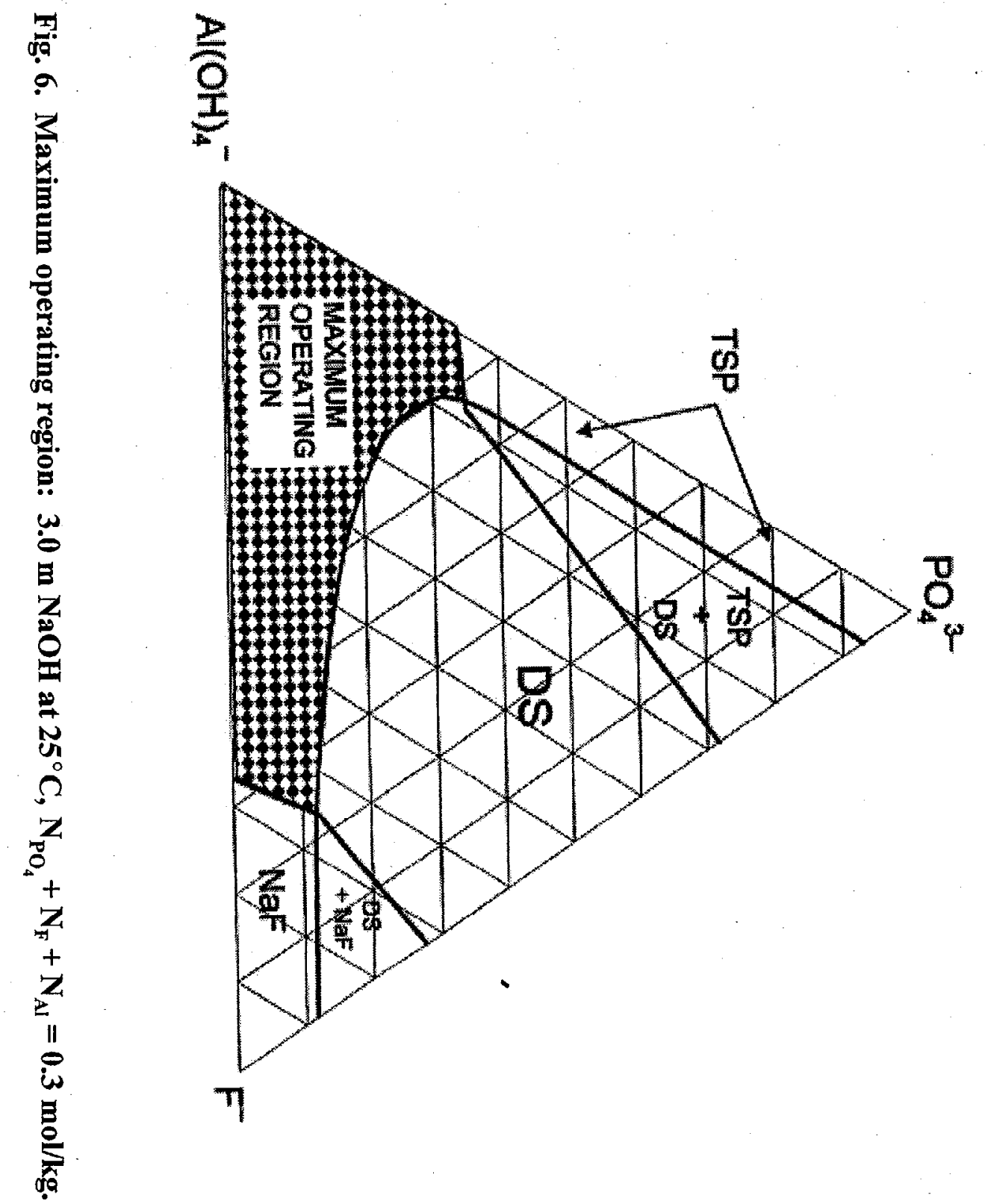




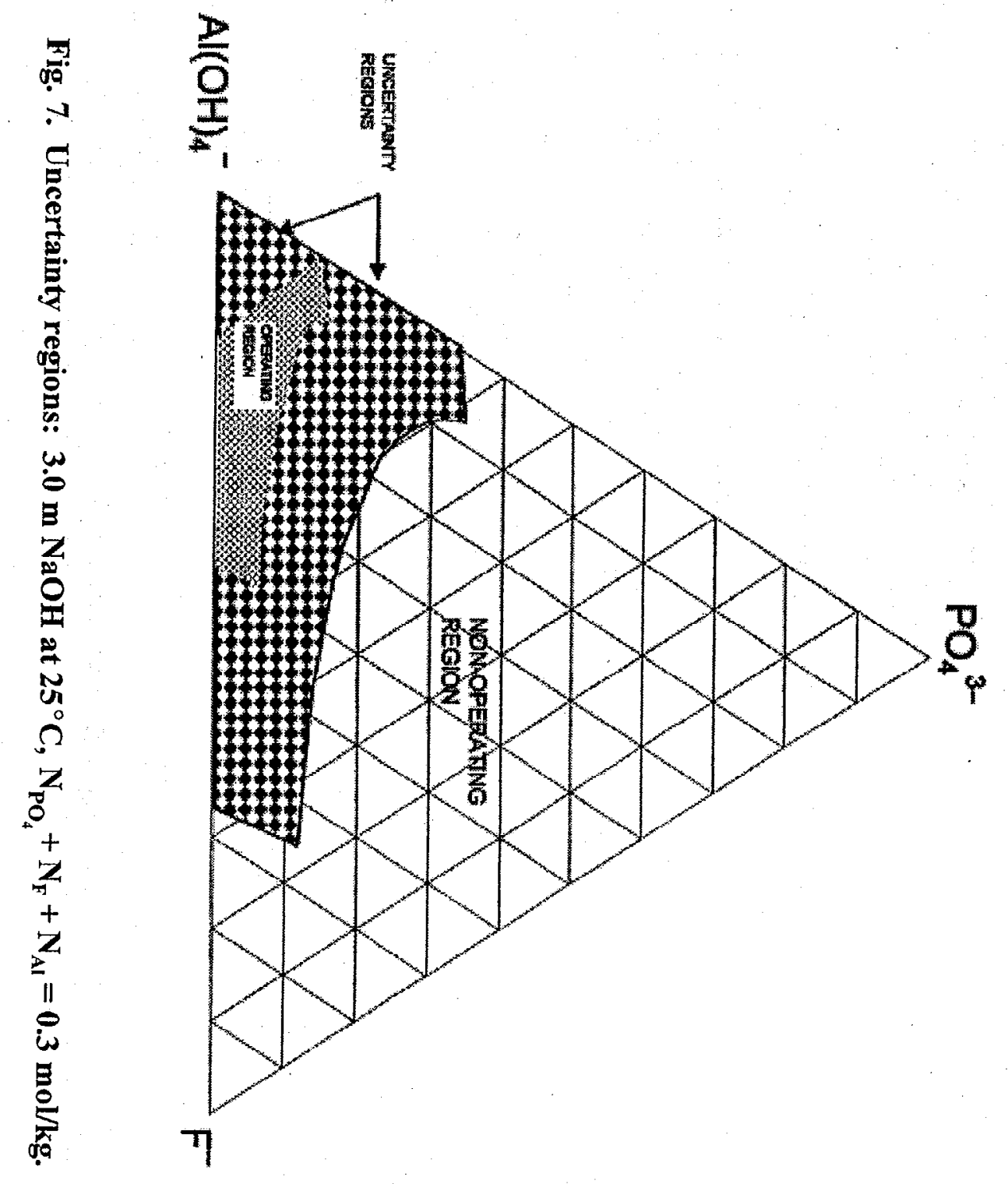




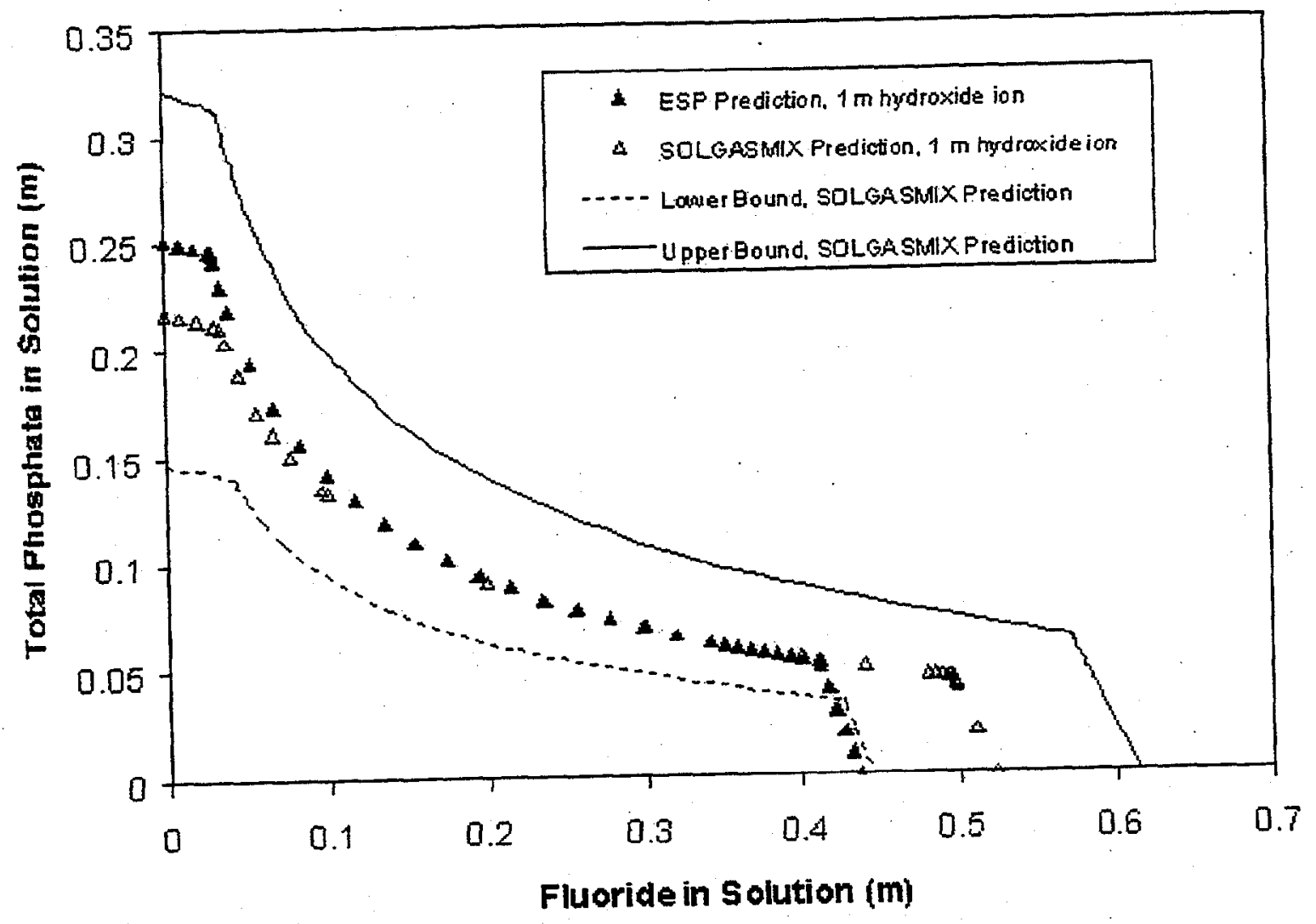

Fig. 8. Comparison calculations for ESP and SOLGASMIX, using $1 \mathrm{~m} \mathrm{NaOH}$ at $25^{\circ} \mathrm{C}$. 


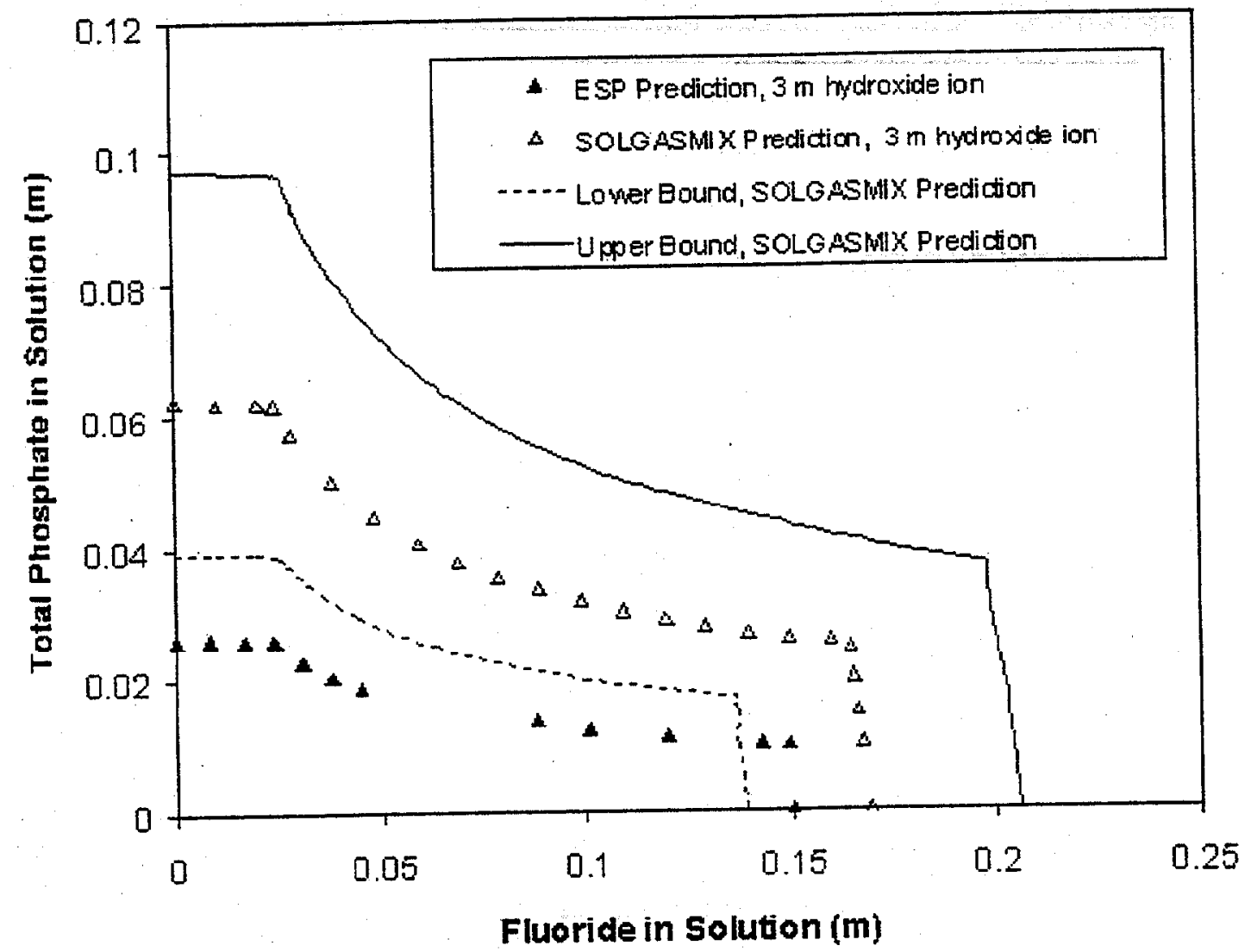

Fig. 9. Comparison calculations for ESP and SOLGASMIX, using $3 \mathrm{~m} \mathrm{NaOH}$ at $25^{\circ} \mathrm{C}$. 


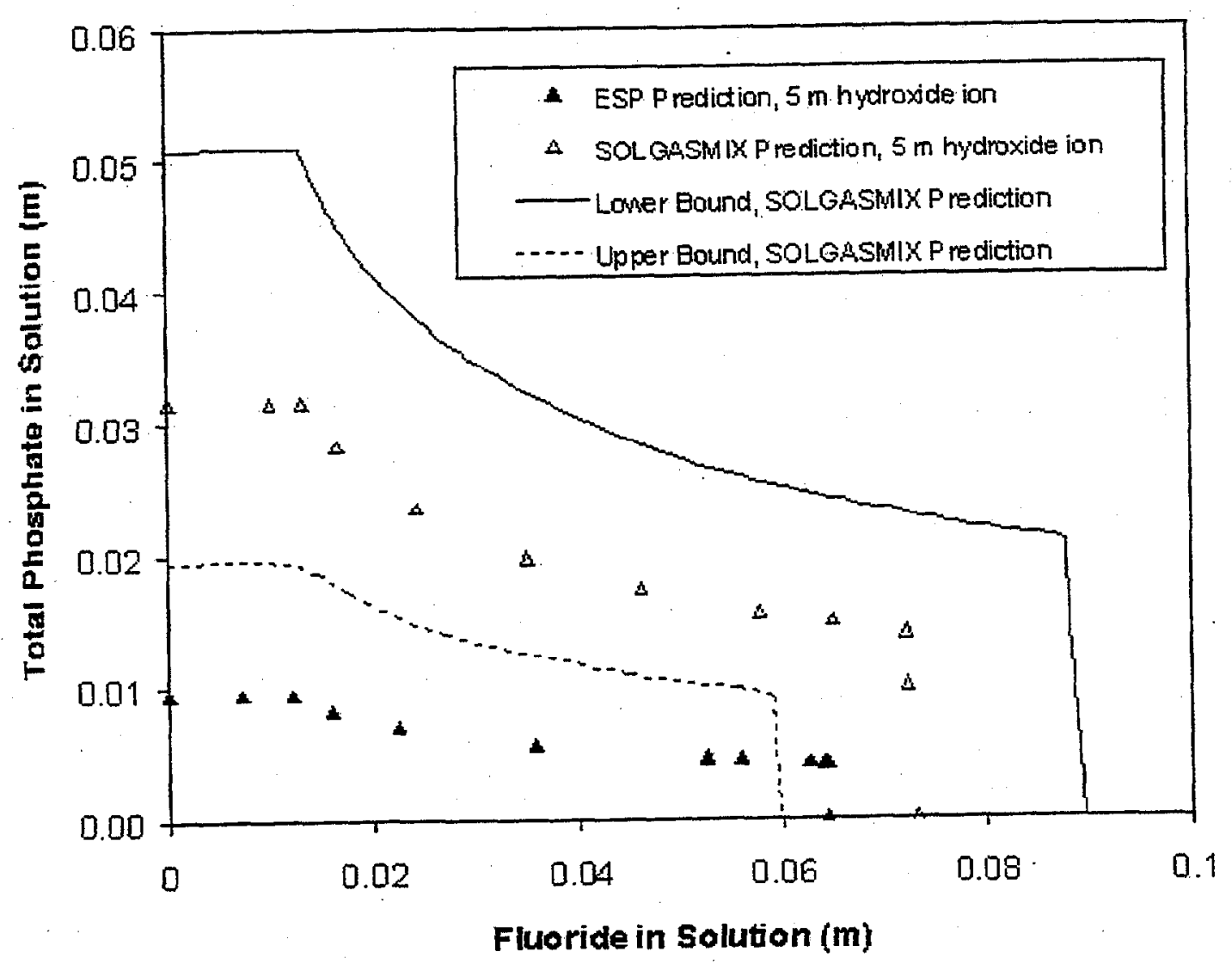

Fig. 10. Comparison calculations for ESP and SOLGASMIX, using $5 \mathrm{~m} \mathrm{NaOH}$ at $25^{\circ} \mathrm{C}$. 


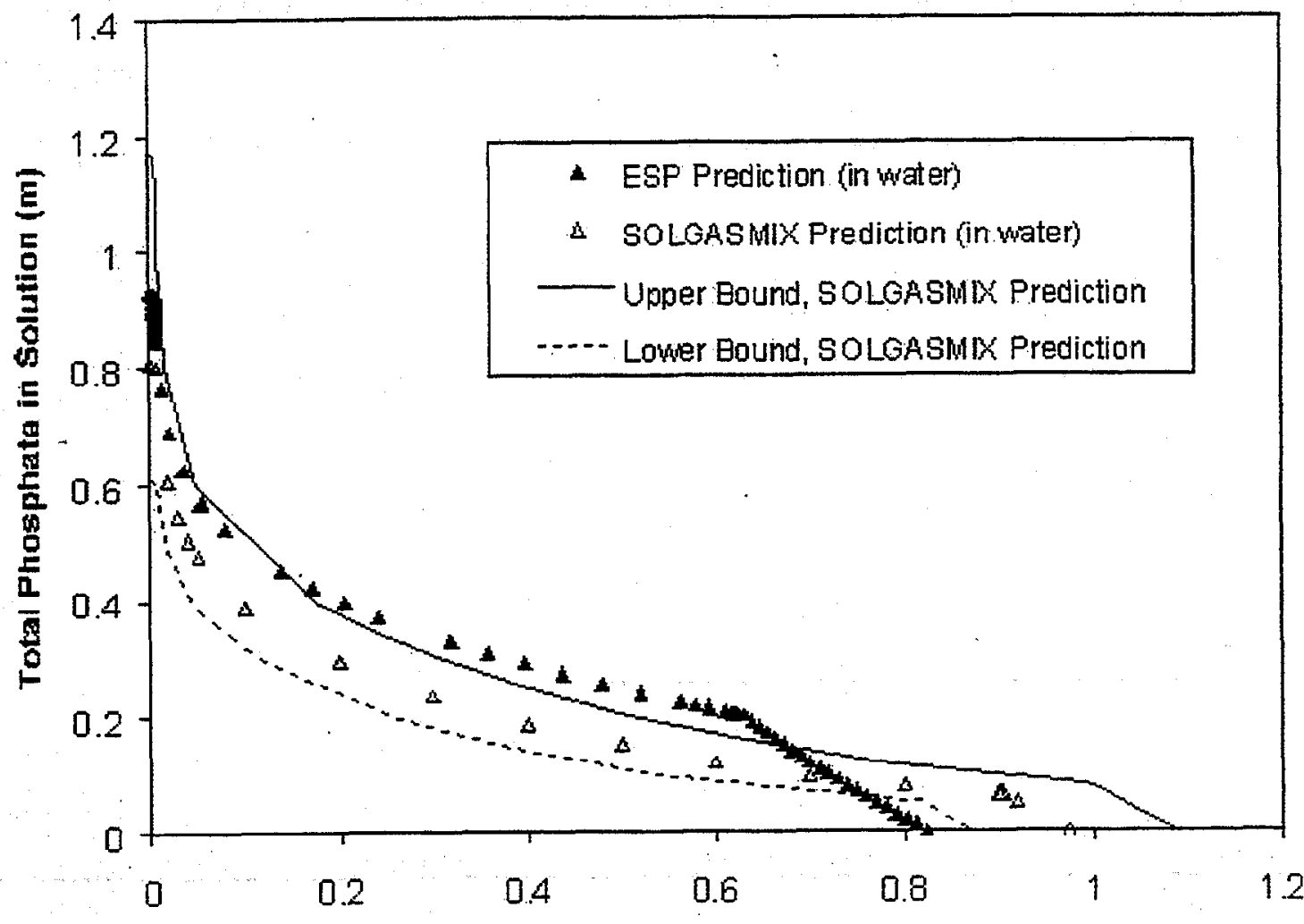

Fluoride in Solution (m)

Fig. 11. Comparison calculations for ESP and SOLGASMIX, using water at $25^{\circ} \mathrm{C}$. 
Figure 8 gives the comparison for $1 \mathrm{~m} \mathrm{NaOH}$ at $25^{\circ} \mathrm{C}$. The solid triangles for the ESP calculations are in close proximity to the open triangles for the SOLGASMIX values, which are based on the mean values (cf. Sect. 2) for the Gibbs energies. The solubilities of trisodium phosphate (ordinate) and sodium fluoride (abscissa) do show some difference.

However, in $3 \mathrm{~m} \mathrm{NaOH}$ solutions (see Fig. 9), the correspondence between the ESP and SOLGASMIX calculations is poor. For most of the solubility curve, the ESP results are below the lower bound of the SOLGASMIX calculations. This means that under these conditions ESP would predict much lower solubility values than would SOLGASMIX. In $5 \mathrm{~m} \mathrm{NaOH}$ solutions, this trend of the ESP results located below the lower bound of the SOLGASMIX calculations persists, as shown in Fig. 10.

On the other hand, in water without added $\mathrm{NaOH}$, the ESP results lie along the upper solubility limit curve of the SOLGASMIX calculations, as shown in Fig. 11.

Because of the similarity in the ESP results and the upper solubility limit of the SOLGASMIX calculations in water, it is reasonable to assume that the Gibbs energy for the sodium phosphate-fluoride double salt in ESP is close to that of the most positive $\mu^{0} / \mathrm{RT}$ value given in Sect. $2.1,-3512.445$. The corresponding value of $\mu / R T$ in ESP was found to be -3510.66 . Also, because the decrease in solubility with increasing $\mathrm{NaOH}$ concentration is greater in the ESP calculations than in the SOLGASMIX results, the ion interactions and activity coefficients of the aqueous species are significantly different. In $1 \mathrm{~m} \mathrm{NaOH}$ solutions the two effects, Gibbs energies and ion interaction/activity coefficients, are such that the ESP and SOLGASMIX calculations coincide for most compositions.

\section{DISCUSSION}

The use of the term "operating region" in Sect. 3 to designate compositions where solids do not form is consistent with the terminology of Ref. 4 . However, the very low concentrations where solids do not form, as demonstrated in Figs. 1-7 and in Ref. 4, indicate that solid formation will be the norm rather than the exception. Therefore, continuing efforts will include evaluations of solid properties with regard to retrieval, transport, and pretreatment, as well as solubility relationships. 
Variations in calculated solubilities can arise from differences in Gibbs energies or activity coefficients. The ranges of uncertainty in Sect. 3 were based on an assessment of uncertainties for the Gibbs energies alone. Based on the calculations in Sects. 3 and 4, two things are apparent: (1) the Gibbs energy in ESP for sodium fluoride-phosphate is near, or more positive than, those assessed here; and (2) the variation in activity coefficients with change in $\mathrm{NaOH}$ is much greater in the ESP calculations.

A noticeable discrepancy in the solubilities of the pure components (sodium fluoride and trisodium phosphate) predicted by ESP and SOLGASMIX is observed at all $\mathrm{OH}^{-}$concentrations examined. Since these solubilities serve to anchor the solubility envelope for the sodium fluoridephosphate double salt, further ESP simulations were carried out to determine the source of these discrepancies. Discussion with engineers from OLI Systems, Inc., revealed that the solubility of a solid species can be predicted within ESP using a temperature-dependent KFIT* expression for the given solid species, ${ }^{8}$ rather than through use of the Gibbs Free Energy of Formation. These KFIT expressions are developed by OLI personnel through fitting of available experimental data for the system of interest. If a KFIT expression is not available for a particular species, the Gibbs Free Energy of Formation in the ESP data base is used, by default, for the solubility calculation.

The pure-component solubilities for sodium fluoride in water and 1,3 , and $5 \mathrm{~m} \mathrm{OH}^{-}$at $25^{\circ} \mathrm{C}$ are compared with the predicted solubilities from SOLGASMIX in Table 3. Values are included from both modes of calculation.

Table 3. Solubility values for sodium fluoride at $25^{\circ} \mathrm{C}$

\begin{tabular}{cccc}
\hline & \multicolumn{3}{c}{ Fluoride ion concentration, $\mathrm{F}^{-}(\mathrm{mol} / \mathrm{kg})$} \\
\cline { 2 - 4 } Solution & SOLGASMIX & ESP-KFIT & ESP- $\Delta \mathrm{G}_{\mathrm{f}}^{0}$ \\
\hline Water & 0.974 & 0.8235 & 0.9425 \\
$1 \mathrm{~m} \mathrm{OH}^{-}$ & 0.524 & 0.4366 & 0.5287 \\
$3 \mathrm{~m} \mathrm{OH}^{-}$ & 0.169 & 0.1506 & 0.1899 \\
$5 \mathrm{~m} \mathrm{OH}^{-}$ & 0.0732 & 0.0646 & \\
\hline
\end{tabular}

\footnotetext{
*Name of option in ESP routine.
} 
At $25^{\circ} \mathrm{C}$ the fluoride ion molality predicted by ESP using the Gibbs Free Energy of Formation agrees fairly well with the SOLGASMIX results. However, there is a significant difference between the predicted solubilities for the fluoride ion when the KFIT expression is used within ESP. Similar behavior is observed for TSP.

Figure 12 provides a comparison of the temperature dependence of the solubility of sodium fluoride predicted by ESP using the Gibbs Free Energy of Formation and the KFIT expression. Two trends are evident in these data. First, as the temperature is increased, the solubility predicted using the Gibbs Free Energy of Formation displays a curvature that is different from that predicted using the KFIT expression. This is probably a manifestation of the specific heat information in the data base. Earlier examination of the thermodynamic data in the ESP data base indicated that the specific heats contained therein were subject to higher uncertainties as compared with the standard thermodynamic reference data compilations $\left(\operatorname{CODATA}^{3}\right)$. The second notable trend is the impact of $\mathrm{OH}^{-}$concentration on the predicted solubility. At higher $\mathrm{OH}^{-}$concentrations, the difference between the solubility envelopes predicted by ESP using $\Delta \mathrm{G}_{\mathrm{f}}{ }^{0}$ and KFIT decreases significantly. ESP comparison calculations at $25^{\circ} \mathrm{C}$ for the solubility envelope of the double salt are under way using the Gibbs Free Energy of Formation. The impact of the pure-component solubility on the location of the invariant points and the double-salt solubility envelope will be examined through comparison with the SOLGASMIX predictions.

The evaluation of uncertainties in SOLGASMIX calculations and the comparison with ESP were based on an important subsystem of the components that would be present in Hanford underground storage tank wastes. In this subsystem, there are significant uncertainties in concentrations where solids form (cf. Figs. 1-7) even though the calculations were based on assessed data. The different results obtained using KFIT and Gibbs Free Energy of Formation expressions within ESP (cf. Fig. 12) were not anticipated. Partly due to this observation of different results for different options in ESP, a Best Practices Guide for ESP will be assembled. 


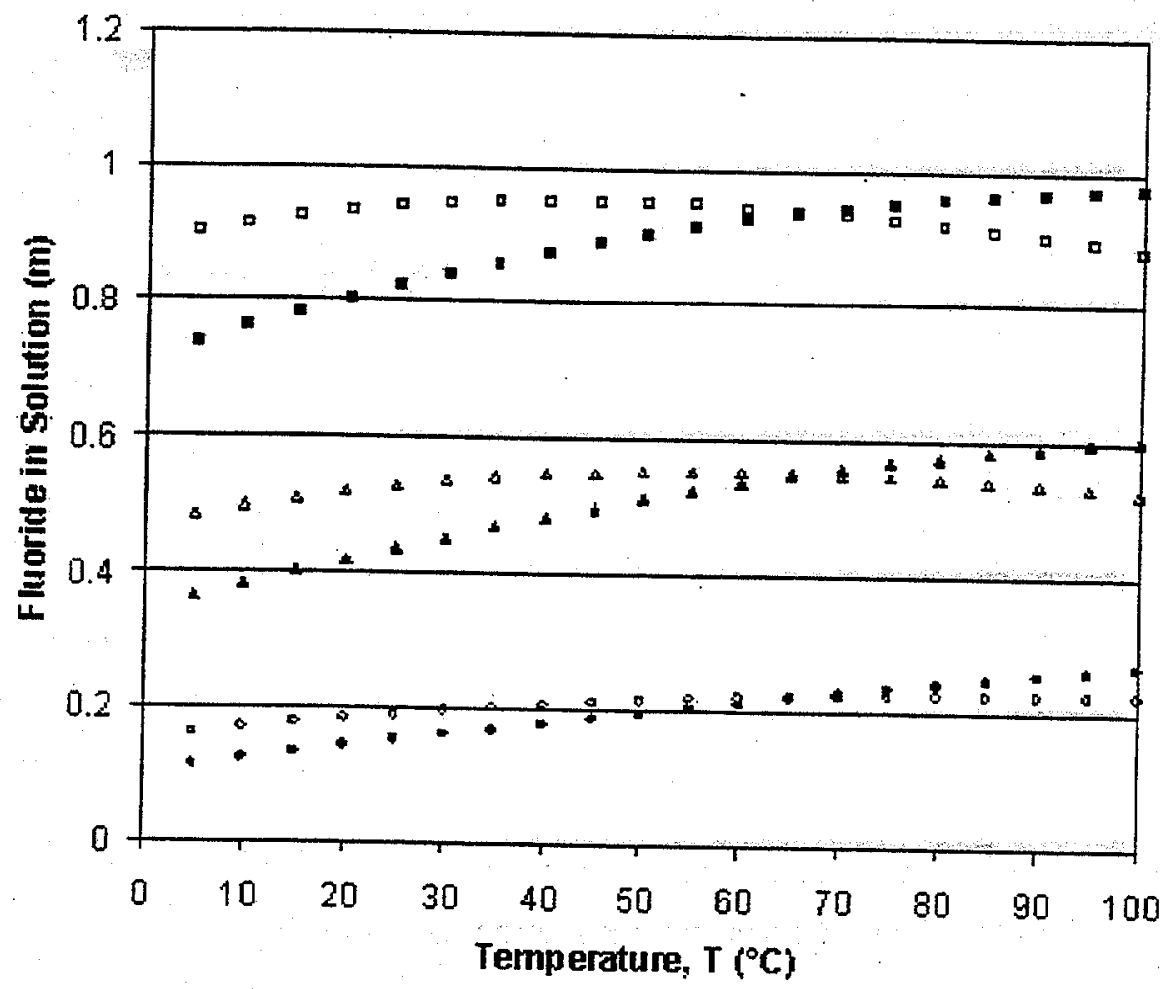

- WRTER - KFIT

- 1 m hydroxjde ion - KF IT

- VIATER - DGt

$1 \mathrm{~m}$ hydnavide ion - DGt

- 3 m hydroxide ion - KFI

- 3 m thydroxide ion-DGf

Fig. 12. Temperature dependence of sodium fluoride solubility. 


\section{REFERENCES}

1. G. Eriksson, "Thermodynamic Studies of High Temperature Equilibria: XII. SOLGASMIX, a Computer Program for Calculation of Equilibrium Compositions in Multiphase Systems," Chem. Scripta 8, 100 (1975).

2. J. D. Cox, D. D. Wagman, and V. A. Medvedev, CODATA: Key Values for Thermodynamics, Hemisphere Publishing, New York, 1989, p. 271.

3. R. K. Toghiani, J. S. Lindner, C. Barfield, and E. C. Beahm, Saltcake Dissolution Modeling, FY 1998, Status Report, DIAL-40395-TR98-1.2, Diagnostic Instrumentation and Analysis Laboratory, Mississippi State University, Starkville, Miss., 1998.

4. E. C. Beahm, C.F. Weber, D. D. Lee, T. A. Dillow, R. D. Hunt, C. M. Keswa, K. Osseo-Asare, and K. E. Spear, Status Report on Solid Control in Leachates, ORNL/TM-13660, Oak Ridge National Laboratory, Oak Ridge, Tenn., July 1998.

5. C. F. Weber, "A Solubility Model for Aqueous Solutions Containing Sodium Fluoride and Sodium Phosphate," Ph.D. dissertation, The University of Tennessee, Knoxville, Tenn., May 1998.

6. D. J. Wesolowski, "Aluminum Speciation and Equilibria in Aqueous Solution: I. The Solubility of Gibbsite in the System Na-K-Cl-OH-Al(OH) $)_{4}$ from 0 to $100^{\circ} \mathrm{C}$," Geochim. Cosmochim. Acta 56(3), 1065-91 (1992).

7. J. A. Apps and J. M. Neil, "Solubilities of Aluminum Hydroxides and Oxyhydroxides in Alkaline Solutions," pp. 416-28 in Chemical Modeling of Aqueous Systems II, Vol.32, ed. D. C. Melchior and R. L. Bassett, American Chemical Society, 1990.

8. R. K. Toghiani, Mississippi State University, Mississippi State, Miss., personal communication to Brian Li, OLI Systems, Inc., Morris Plaines, N. J., April 1999. 